\title{
Cycling and at-rest stabilities of a complementary electrochromic device based on tungsten oxide and Prussian blue thin films
}

\author{
Kuo-Chuan Ho* \\ Department of Chemical Engineering, National Taiwan University, Taipei, 10617, Taiwan
}

Received 17 September 1998; received in revised form 9 November 1998

\begin{abstract}
Complementary tungsten oxide $\left(\mathrm{WO}_{3}\right)$-Prussian blue $(\mathrm{PB})$ electrochromic devices (ECDs), in combination with $\mathrm{Li}^{+}, \mathrm{K}^{+}$or $\mathrm{H}^{+}$-based electrolytes, have been proposed by many researchers for solar attenuation and glare reduction applications. In this study, cycling and at-rest stabilities of a solid-state ECD comprised of a $\mathrm{WO}_{3}$ and $\mathrm{PB}$ thin film couple with a proton-conducting solid polymer electrolyte are discussed. The transmittance of the device varied from $71.5 \%$ to $6.0 \%$ at $550 \mathrm{~nm}$. The device was darkened or bleached by the application of $+1.2 \mathrm{~V}$ or -0.6 V, respectively. Repeated switching or cycling of the ECD over 20,000 cycles has been demonstrated, indicating a large number of switchings without great degradation or irreversible side reactions. Nevertheless, at-rest stability in the absence of cycling, at room temperature over months, has not been achieved. The cause of at-rest instability during darkened-state or bleached-state storage will be discussed. Issues related to the scale-up are also discussed. (C) 1999 Elsevier Science Ltd. All rights reserved.
\end{abstract}

Keywords: Degradation; Electrochromic; Prussian blue; Stability; Tungsten trioxide

\section{Introduction}

Recently, complementary tungsten oxide-Prussian blue $(\mathrm{PB})$ electrochromic devices (ECDs), in combination with $\mathrm{Li}^{+}, \mathrm{K}^{+}$or $\mathrm{H}^{+}$-based electrolytes, have been proposed by many researchers [1-15] for solar attenuation and glare reduction applications. A partial list of complementary, electrochromic configurations using the $\mathrm{WO}_{3}-\mathrm{PB}$ couple is given in Table 1 .

Tada et al. [1-3] reported an electrochromic device based on the $\mathrm{WO}_{3}-\mathrm{PB}$ couple using a polyethylene oxide-based polyurethane (PU) network containing

\footnotetext{
* Fax: + 886-2-23623040.

E-mail address: kcho@ms.cc.ntu.edu.tw (K.C. Ho)
}

$\mathrm{KCF}_{3} \mathrm{SO}_{3}$ electrolyte. The solar transmittance of the device varied between 56 and $14 \%$. Habib et al. [4] constructed a device based on the $\mathrm{WO}_{3}-\mathrm{PB}$ couple with the polymer electrolyte prepared from polyvinyl alcohol (PVA) doped with $\mathrm{H}_{3} \mathrm{PO}_{4}$ and $\mathrm{KH}_{2} \mathrm{PO}_{4}$. The electrolyte accommodates both $\mathrm{H}^{+}$and $\mathrm{K}^{+}$ions, $\mathrm{H}^{+}$ for $\mathrm{WO}_{3}$ and $\mathrm{K}^{+}$for $\mathrm{PB}$ insertion-extraction. The transmittance of the device varied from 52 to $12 \%$ at $690 \mathrm{~nm}$. With a $\mathrm{Li}^{+}$-doped oxymethylene polyoxyethylene (OMPE) electrolyte, Habib et al. [5] fabricated a device based also on the $\mathrm{WO}_{3}-\mathrm{PB}$ couple. The transmittance of the device varied from 63 to $32 \%$ at 790 nm. Oyama et al. [6] reported a device based on the $\mathrm{WO}_{3}-\mathrm{PB}$ couple while dispersing $\mathrm{LiCF}_{3} \mathrm{SO}_{3}$ in the intermolecular complex of poly(acrylic acid)-poly(ethylene oxide) electrolyte (PAA-PEO). No switching data 
Table 1

A partial list of ECDs containing the $\mathrm{WO}_{3}-\mathrm{PB}$ couple. $\mathrm{BC}=$ butylene carbonate, HEMA=2-hydroxyethylmethacrylate, $\mathrm{NPG}=$ neopentylglycoldimethacrylate, $\mathrm{OMPE}=$ oxymethylene poly(oxyethylene), $\mathrm{PAA}=$ poly $($ acrylic acid), $\mathrm{PC}=$ propylene carbonate, $\mathrm{PEO}=$ poly $($ ethylene oxide $), \mathrm{PEOS}=$ hybrid of poly(ethylene oxide $)$ and polysiloxane, $\mathrm{P}(\mathrm{MEO}-\mathrm{MAAM})=$ copolymer of oligo(oxyethylene) methacrylate (MEO) and methacrylic acid alkali metal salts (MAAM), Poly-AMPS=poly(2-acrylamido-2methylpropane sulfonic acid), PU = polyurethane, PVA= polyvinyl alcohol, P(VSA-VP)=copolymer of vinylsulfonic acid $(\mathrm{VSA})$ and 1-vinyl-2-pyrrolidinone (VP)

\begin{tabular}{|c|c|}
\hline Configurations & References \\
\hline $\mathrm{K}_{x} \mathrm{WO}_{3} / \mathrm{KCF}_{3} \mathrm{SO}_{3}$ in PEO-based $\mathrm{PU} / \mathrm{PB}$ & {$[1-3]$} \\
\hline $\mathrm{K}_{x} \mathrm{WO}_{3} / \mathrm{H}_{3} \mathrm{PO}_{4}-\mathrm{KH}_{2} \mathrm{PO}_{4}$ in PVA/PB & [4] \\
\hline $\mathrm{Li}_{x} \mathrm{WO}_{3} / \mathrm{Li}^{+}-\mathrm{OMPE} / \mathrm{PB}$ & {$[5]$} \\
\hline $\mathrm{Li}_{x} \mathrm{WO}_{3} / \mathrm{LiCF}_{3} \mathrm{SO}_{3}$ in $\mathrm{PAA}-\mathrm{PEO} / \mathrm{PB}$ & [6] \\
\hline $\mathrm{Li}_{x} \mathrm{WO}_{3} / \mathrm{LiClO}_{4}$ in $\mathrm{PC} / \mathrm{PB}$ & [7-11] \\
\hline $\mathrm{Li}_{x} \mathrm{WO}_{3} / \mathrm{LiClO}_{4}$ in PEOS swollen with PC/PB & [12] \\
\hline $\mathrm{M}_{x} \mathrm{WO}_{3} / \mathrm{P}(\mathrm{MEO}-\mathrm{MAAM}) \mathrm{PB}\left(\mathrm{M}^{+}=\mathrm{Li}^{+}, \mathrm{Na}^{+}, \mathrm{K}^{+}, \mathrm{Rb}^{+}, \mathrm{Cs}^{+}\right)$ & [13] \\
\hline $\mathrm{Li}_{x} \mathrm{WO}_{3} / \mathrm{LiClO}_{4}$ in $(\mathrm{HEMA}-\mathrm{NPG})+\mathrm{PC}+\mathrm{BC} / \mathrm{PB}$ & {$[14]$} \\
\hline $\mathrm{H}_{x} \mathrm{WO}_{3} /$ Poly-AMPS $/ \mathrm{PB}$ & {$[15]$} \\
\hline $\mathrm{H}_{x} \mathrm{WO}_{3} / \mathrm{P}(\mathrm{VSA}-\mathrm{VP}) / \mathrm{PB}$ & This work \\
\hline
\end{tabular}

${ }^{\text {a }}$ AMPS is a registered trademark of Lubrizol Corporation.

were reported. Miyamoto et al. [7] described a $\mathrm{WO}_{3}^{-}$ PB device based on using $1 \mathrm{M} \mathrm{LiClO}_{4}$ in propylene carbonate (PC) as the electrolyte. Transmittances were varied from 60 to $10 \%$, although the wavelength was not specified. Inaba et al. [8] disclosed an electrochromic device having the $\mathrm{WO}_{3}-\mathrm{PB}$ couple and an auxiliary electrode disposed in a marginal region of the space between the two complementary electrodes; an electrolyte occupies the remaining space. The electrolyte was $1 \mathrm{M} \mathrm{LiClO}_{4}$ in PC. The auxiliary electrode serves for two purposes: (1) to provide a means for the initial darkening of the $\mathrm{WO}_{3}$ electrode or for the initial bleaching of the PB electrode and (2) to recover the device's performance due to the loss of the redox balance between the two electrochromic layers, either by repeated darkening-bleaching or by the influence of an impurity in the electrolyte. Kawai et al. [9] disclosed a device similar to the one mentioned by Inaba et al. [8]. However, conjugated polymers were used as the electrochemically oxidizable and reducible materials for the auxiliary electrode because of higher charge-carrying capabilities. This modification was needed for the proper function of the auxiliary electrode, especially for a large-area electrochromic device. Kase et al. $[10,11]$ reported a device based on the $\mathrm{WO}_{3}-\mathrm{PB}$ couple by using a $1 \mathrm{M} \mathrm{LiClO}_{4}$ in $\mathrm{PC}$ with $1-2 \% \mathrm{H}_{2} \mathrm{O}$ as the electrolyte. Typical luminous transmittances in the darkened state were $5-10 \%$, while those of the bleached state were $50-70 \%$. Honda et al. [12] described a solidstate ECD composed of the $\mathrm{WO}_{3}-\mathrm{PB}$ couple in conjunction with a solid hybrid electrolyte of poly(ethylene oxide) and polysiloxane (PEOS) containing $\mathrm{LiClO}_{4}$. The transmittance of the device at $550 \mathrm{~nm}$ was $65 \%$ in the bleached state and $14 \%$ in the darkened state.
However, the bleached-state transmittance decayed from 65 to $57.5 \%$ at the end of 10 th cycle. The decay of the $\mathrm{Li}_{x} \mathrm{WO}_{3}-\mathrm{LiClO}_{4}$ in PEOS-PB device is attributed to the intrinsic electroactivity of PEOS, as no decay was observed for the corresponding liquid ECD. Ohno et al. [13] prepared an all solid-state ECD based on the $\mathrm{WO}_{3}-\mathrm{PB}$ couple and a copolymer of oligo(oxyethylene) methacrylate (MEO) and methacrylic acid alkali metal salts (MAAM). The effect of cation species on both the ionic conductivity and coloring rate of the ECD was studied. Reversible coloring-bleaching characteristics were found when $\mathrm{Li}^{+}, \mathrm{Na}^{+}$and $\mathrm{K}^{+}$conductive polymers were used. Among them, $\mathrm{K}^{+}$ showed the best results in performance because of higher ionic conductivity and smaller ionic size. Inaba et al. [14] fabricated a device with the $\mathrm{WO}_{3}-\mathrm{PB}$ couple using a copolymer of 2-hydroxyethylmethacrylate (HEMA) and neopentylglycoldimethacrylate (NPG) containing $\mathrm{LiClO}_{4}$ and organic solvents of butylene carbonate (BC) and propylene carbonate (PC). The transmittance of the device at $650 \mathrm{~nm}$ varied from 80 to $15 \%$. The transmittance response lost only less than $10 \%$ of its initial magnitude after 100,000 cycles. Ho et al. [15] reported the compatibility of the $\mathrm{WO}_{3}-\mathrm{PB}$ couple with a proton-conducting polymer electrolyte. Although electrochemical stability for at least 20,000 cycles at room temperature has been achieved for the proton-based $\mathrm{H}_{x} \mathrm{WO}_{3} /$ Poly-AMPS/PB system, instability at-rest, even at room temperature over months, was observed.

Generally speaking, at least three stability issues need to be addressed before any successful electrochromic systems can be realized. These are electrochemical, thermal and at-rest stabilities. Many researchers have 


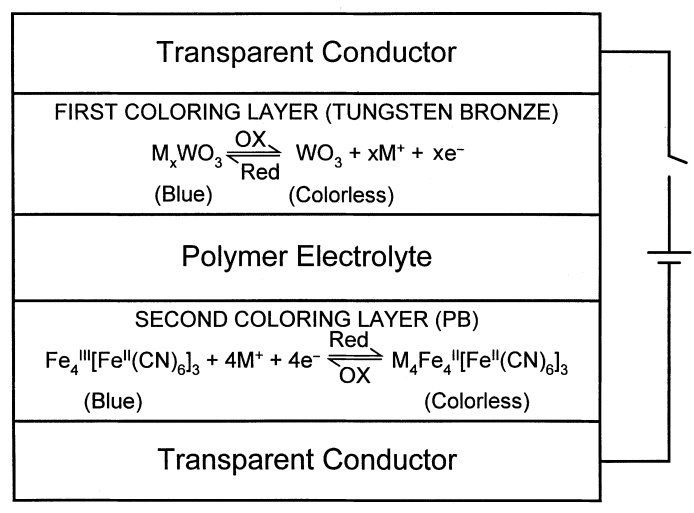

Fig. 1. Principle of electrochromic switching for $\mathrm{M}_{x} \mathrm{WO}_{3}-$ Polymer Electrolyte-PB $\left(\mathrm{M}^{+}=\mathrm{H}^{+}, \mathrm{Li}^{+}, \mathrm{Na}^{+}, \mathrm{K}^{+}, \mathrm{Rb}^{+}\right.$ and $\mathrm{Cs}^{+}$).

reported about electrochemical and/or thermal stabilities for prospective configurations, as documented by Czanderna and Lampert [16]. However, very little information about at-rest stability is available for comparison. In this paper, at-rest stability will be emphasized. At-rest stability, or really instability, has evolved as another issue in addition to electrochemical and thermal stabilities; it probably is a predictor of the latter. The configuration of $\mathrm{H}_{x} \mathrm{WO}_{3} / \mathrm{H}^{+}$-solid polymer electrolyte $(\mathrm{SPE}) / \mathrm{PB}$ is presented in which the $\mathrm{H}^{+}$solid polymer electrolyte is based on the copolymer of sodium vinylsulfonic acid $\left(\mathrm{Na}^{+}\right.$-vsa) and 1-vinyl-2-pyrrolidinone (vp) [17-19]. This class of copolymer electrolytes, when synthesized with an appropriate molar ratio of co-monomer, is stable at temperatures as high as $90^{\circ} \mathrm{C}$ continuously for over a month [18], making it an ideal candidate to be incorporated in $\mathrm{a} \mathrm{H}^{+}$-based electrochromic system for studying electrochemical, thermal and at-rest stabilities.

Even though the electrochromic switching reactions involving $\mathrm{WO}_{3}$ and $\mathrm{PB}$ electrodes, as shown in Fig. 1, are well known, one of difficulties in studying the general stability of the electrochromic system is the lack of reproducibility; that is, electrochromic performance varies from one sample to the other, even for two samples supposedly made under the same conditions. Drifting data for the bleached and darkened states exhibit a lot of scatter, making direct study difficult. This is due to the early oxidation of the precharged $\mathrm{WO}_{3}$ in air; the rate and degree of oxidation varies from plate to plate. A procedure has been established in this study for precharging the $\mathrm{WO}_{3}$ plate in the copolymer electrolyte solution, rather than $\mathrm{HCl}$, so as to minimize oxidation in air. This seems to work very well for half cells consisting of copolymer $/ \mathrm{H}_{x} \mathrm{WO}_{3} /$ conducting glass. The purpose is to attain better control of the charge balance between $\mathrm{WO}_{3}$ and $\mathrm{PB}$ electrodes during cell assembly and gain more reproducible performance afterward. Therefore, it is important to examine the connection between the optical attenuation range, or the transmittance switching window and the charge capacity ratio of $\mathrm{H}_{x} \mathrm{WO}_{3}$ relative to PB.

\section{Experimental}

\section{1. $\mathrm{WO}_{3}$ working electrode}

The experimental procedures for preparation of $\mathrm{WO}_{3}$ were described elsewhere [20]. $\mathrm{WO}_{3}$ was vacuumdeposited on fluorine-doped tin oxide (FTO) coated glass substrates. The sheet resistance of FTO-coated glass substrates was measured by the four-point probe method and was $10 \Omega$ /square. Conductive copper bus bars were applied on all four sides of the FTO-coated substrate. FTO-coated glass substrates (size A: $6.0 \times$ $7.0 \times 0.23 \mathrm{~cm}^{3}$, size B: $13.0 \times 17.5 \times 0.23 \mathrm{~cm}^{3}$, size $\mathrm{C}$ : $17.5 \times 43.0 \times 0.23 \mathrm{~cm}^{3}$ and size D: $43.0 \times 43.0 \times 0.23$ $\mathrm{cm}^{3}$ ) were precleaned ultrasonically in an aqueous cleaner solution reported previously [20,21]. Tungsten oxide films prepared in this way had a thickness of 370 $\pm 50 \mathrm{~nm}$. X-ray diffraction analysis, with a Rigaku diffractometer (Model D-2655) using monochromatized $\mathrm{Cu} K_{\alpha}$ incident radiation, showed all the films to be lacking crystallinity.

\subsection{Prussian blue counterelectrode}

The sacrificial anode (SA) method, which is based on the cathodic electrodeposition (ED) mentioned by Ellis et al. [22] for PB deposition, was modified and used in this work. The modified sacrificial method for PB deposition was described elsewhere [23]. The solution contained $5 \mathrm{mM}$ of $\mathrm{FeCl}_{3} \cdot 6 \mathrm{H}_{2} \mathrm{O}$ and $5 \mathrm{mM}$ of $\mathrm{K}_{3} \mathrm{Fe}(\mathrm{CN})_{6}$. It takes about 30 minutes to deposit the desired amount of PB on FTO-coated glass. The thickness of the PB film was controlled at $475 \pm 25 \mathrm{~nm}$ by counting the passed charge, which is proportional to the amount of PB deposited. In all cases, the charge capacity for the deposition was controlled at $13.2 \mathrm{mC} /$ $\mathrm{cm}^{2}$. X-ray diffraction analysis, with a Rigaku diffractometer (Model D-2655), using monochromatized $\mathrm{Cu}$ $K_{\alpha}$ incident radiation, showed all the films to be crystalline.

\subsection{Solid polymer electrolyte}

The transparent electrolyte is the copolymer based on the copolymerization of sodium vinylsulfonic acid $\left(\mathrm{Na}^{+}\right.$-vsa) and 1-vinyl-2-pyrrolidinone (vp) [18]. The sodium form of this copolymer is exchanged to the acid form for use as the electrolyte in electrochromic 
devices. $\mathrm{Na}^{+}$-vsa/vp copolymerization is intentionally done with a slightly enriched vp than desired. 1.6:1 $\mathrm{Na}^{+}$-vsa/vp to obtain $\sim 2: 1$ poly $\left(\mathrm{Na}^{+}\right.$-vsa/vp) copolymer for example.

\subsection{Cell assembly}

Before assembling the cells, the $\mathrm{WO}_{3}$ electrode was precharged with protons. A constant current density of $0.11 \mathrm{~mA} / \mathrm{cm}^{2}$ was used in cathodizing the tungsten oxide electrode. It takes about $4 \mathrm{~min}$ to get the proper amount of protons into the tungsten oxide thin film. For $\mathrm{WO}_{3}$ electrodes with sizes $\mathrm{C}$ and $\mathrm{D}$, it is necessary to employ multiple bus bars on the $\mathrm{WO}_{3} /$ conducting glass substrate to ensure a uniform precharging condition. The tungsten bronze, $\mathrm{H}_{x} \mathrm{WO}_{3}$, was then rinsed with distilled water and dried under $\mathrm{N}_{2}$. The polymer electrolyte was flow coated on both electrodes. Conditioning was done in a room with controlled relative humidity of $35 \%$ at $23^{\circ} \mathrm{C}$. Cells were intimately laminated together with $\mathrm{H}_{x} \mathrm{WO}_{3}$ as the working electrode and $\mathrm{PB}$ as the counterelectrode. The lamination was carried out in an autoclave at a pressure of $1.03 \times$ $10^{6} \mathrm{~N} / \mathrm{m}^{2}$ and a temperature of $93^{\circ} \mathrm{C}$ for one hour [24]. This procedure resulted in an averaged thickness of $100 \mu \mathrm{m}$ for the copolymer electrolyte, as measured by a micrometer across samples. After autoclaving, each cell was sealed around all four edges with butyl rubber. The electroactive areas of the ECDs with four sizes were (A): $4.8 \times 5.4 \mathrm{~cm}^{2},(\mathrm{~B}): 10.2 \times 15.2 \mathrm{~cm}^{2},(\mathrm{C}): 16.0$ $\times 41.5 \mathrm{~cm}^{2}$ and (D): $41.7 \times 41.7 \mathrm{~cm}^{2}$. In the case of making cells for refreshing purpose, a third Pt electrode, in the form of a strip (thin foil), was embedded in a copolymer-primed Nafion 117 membrane $(0.018$ $\mathrm{cm}$ thick). The embedded Pt electrode served to provide an internal charge balance for the $\mathrm{WO}_{3}$ electrode. This configuration is designated as $\mathrm{H}_{x} \mathrm{WO}_{3} / \mathrm{P}(\mathrm{VSA}-$ VP)-primed Nafion/Pt/PB. The autoclave lamination conditions were slightly changed to $1.38 \times 10^{6} \mathrm{~N} / \mathrm{m}^{2}$ and $121^{\circ} \mathrm{C}$ for one hour to give the best results in terms of lamination.

\subsection{Electrochemical runs}

The coloration and bleaching of cells were carried out by applying a constant dc voltage (Keithley voltage/current source, Model 228A). The transmittance, current and the drift of the cell voltage were recorded. The change in optical transmittance during coloration and bleaching was measured at $550 \mathrm{~nm}$ with a Cary-14 spectrophotometer. Transmittance data were taken at or near the center of each cell, depending on the size of the sample.

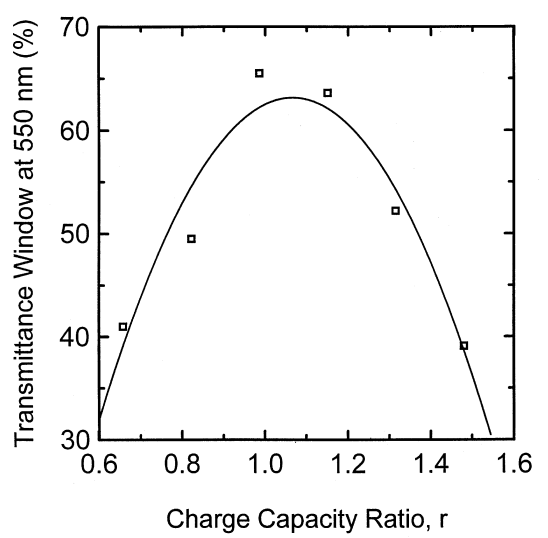

Fig. 2. Transmittance window at $550 \mathrm{~nm}$ vs. charge capacity ratio for a device of size $\mathrm{B}$, with an active area of $155.0 \mathrm{~cm}^{2}$.

\section{Results and discussion}

\subsection{Charge capacity ratio}

$\mathrm{WO}_{3}$ electrodes (size $\mathrm{B}$, active area $=10.2 \times 15.2$ $\mathrm{cm}^{2}$ ) were precharged in copolymer solution in order to optimize precharging conditions, to match the charge capacity of the PB electrode of the same size (size $\mathrm{B}$ ). The $\mathrm{WO}_{3}$ electrodes were precharged at different proton levels just before cells were put together. Fig. 2 indicates the initial transmittance window measured at $550 \mathrm{~nm}, \Delta T_{550, t=0} \equiv T_{b, t=0}-T_{d, t=0}$, against the ratio of charge capacity, $q$, of the $\mathrm{H}_{x} \mathrm{WO}_{3}$ to that of the $\mathrm{PB}, r \equiv q_{\mathrm{H}_{x} \mathrm{WO}_{3}} / q_{\mathrm{PB} \rightarrow \mathrm{PW}}$, where $T_{\mathrm{b}}$ and $T_{\mathrm{d}}$ are bleached and darkened state transmittances, respectively. The charge capacity of the $\mathrm{H}_{x} \mathrm{WO}_{3}$, denoted by $q_{\mathrm{H}_{x} \mathrm{WO}_{3}}$, is the amount of charge injected per unit area of electrode. The charge capacity of the PB, denoted by $q_{\mathrm{PB} \rightarrow \mathrm{PW}}$, is the charge consumption per unit electrode area in reducing $\mathrm{PB}$ to Prussian white (PW). The value of $q_{\mathrm{PB} \rightarrow \mathrm{PW}}$ was determined experimentally by switching the PB electrode in the copolymer solution cathodically at $-0.6 \mathrm{~V}$ against a $\mathrm{Pt}$ electrode. The value of $q_{\mathrm{PB} \rightarrow \mathrm{PW}}$ is $21.61 \mathrm{mC} / \mathrm{cm}^{2}$ for a PB electrode of size B, with an active area of 155.0 $\mathrm{cm}^{2}$. The precharging capacities on the tungsten oxide electrode were varied from 14.22, 17.78, 21.33, 24.89, 28.44 and $32.00 \mathrm{mC} / \mathrm{cm}^{2}$, corresponding to the charge capacities ratio of $0.66,0.82,0.99,1.15,1.32$ and 1.48 , respectively. It was interesting to find experimentally that the closer the ratio of two charge capacities to unity $(r \rightarrow 1.0)$, the wider the transmittance window or attenuation. In fact, this result is expected by considering the general charge limitation model in a complementary electrochromic system as proposed by Rauh and Cogan [25].

Furthermore, Fig. 2 can be used to explain the clos- 


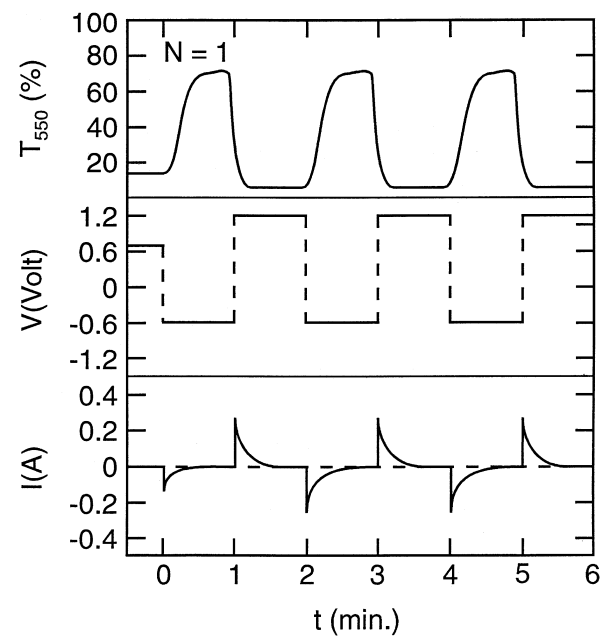

Fig. 3. The transmittance (at $550 \mathrm{~nm}$ ) and current density during cyclic potentiostatic switching for $\mathrm{H}_{x} \mathrm{WO}_{3} / \mathrm{P}(\mathrm{VSA}-$ $\mathrm{VP}) / \mathrm{PB}$ configuration of size $\mathrm{B}$.

ing of the transmittance window, as a result of irreversible oxidation of the $\mathrm{H}_{x} \mathrm{WO}_{3}$ electrode, when a cell is left at rest in the darkened state. It is therefore inferred that the key to approaching at-rest stability lies in the ability to first generate and then to maintain balanced charge capacity between the working and the counterelectrodes over extended periods of time. A similar trend in $\Delta T_{550, t=0}$ vs. $r$ for cells made of electrode of size A, with active area of $4.8 \times 5.4 \mathrm{~cm}^{2}$, were observed. In this case, the value of $q_{\mathrm{PB} \rightarrow \mathrm{PW}}$, determined experimentally, was found to be $28.47 \mathrm{mC} / \mathrm{cm}^{2}$.

\subsection{Electrochromic performance}

The transmittance (at $550 \mathrm{~nm}$ ) at geometric center

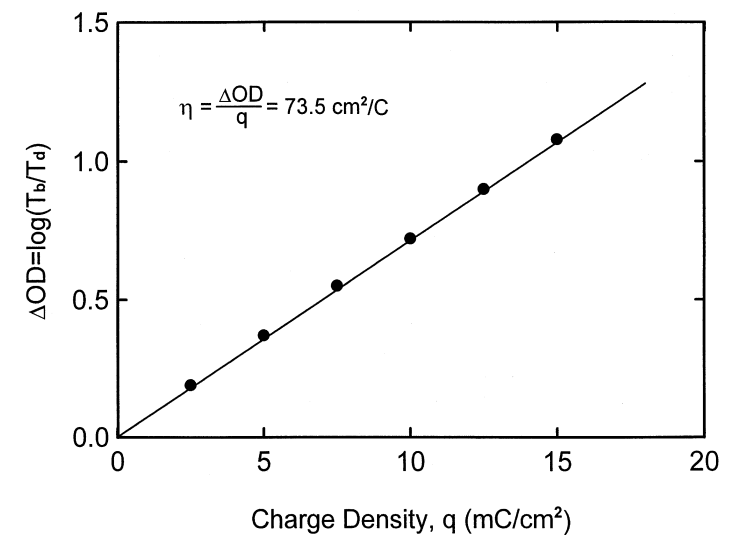

Fig. 4. Change of optical density at $550 \mathrm{~nm}$ as a function of charge injection/ejection per unit area. Data are shown for a fresh sample of size B.

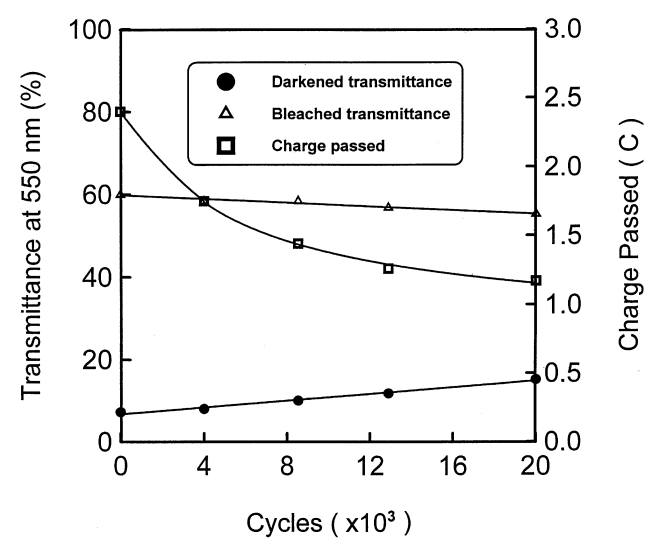

Fig. 5. Transmittance variations at $550 \mathrm{~nm}$ and charge passed as a function of cycling for $\mathrm{a}_{x} \mathrm{WO}_{3} / \mathrm{P}(\mathrm{VSA}-\mathrm{VP}) / \mathrm{PB}$ cell of size $\mathrm{B}$, showing some electrochemical instability up to 20,000 cycles.

and current during cyclic potentiostatic switching, for a typical sample with size $\mathrm{B}$, is presented in Fig. 3 for the first three cycles. The sample was darkened or bleached by the application of +1.2 or $-0.6 \mathrm{~V}$, respectively. The voltage is the potential difference between the PB electrode and the tungsten oxide electrode $\left(\mathrm{PB}\right.$ vs. $\left.\mathrm{WO}_{3}\right)$. These voltages are within the electrochemically safe voltage limits, which were predetermined from cyclic voltammetry of the cell with the current configuration of $\mathrm{H}_{x} \mathrm{WO}_{3} / \mathrm{P}(\mathrm{VSA}-\mathrm{VP}) / \mathrm{PB}$. Fig. 4 is a plot of the optical density change at 550 $\mathrm{nm}, \Delta \mathrm{OD}$, as a function of the charge injected/ extracted per unit area, $q$. This is shown for a fresh sample of size B. Darkening was done at room temperature. The coloration efficiency of the device is determined from the slope and is $73.5 \mathrm{~cm}^{2} / \mathrm{C}$ at 550 $\mathrm{nm}$. This value is very close to $75.1 \mathrm{~cm}^{2} / \mathrm{C}$, a value reported earlier [15] for a sample of similar size (electroactive area $=11.5 \times 15.5 \mathrm{~cm}^{2}$ ) with the configuration $\mathrm{H}_{x} \mathrm{WO}_{3} /$ Poly-AMPS/PB. This implies that the present configuration, $\mathrm{H}_{x} \mathrm{WO}_{3} / \mathrm{P}(\mathrm{VSA}-\mathrm{VP}) / \mathrm{PB}$, also exhibits a successful insertion/extraction of protons into and out of both tungsten oxide and PB films. Fig. 5 shows the relatively satisfactory cycling stability with the $\mathrm{H}_{x} \mathrm{WO}_{3} / \mathrm{P}(\mathrm{VSA}-\mathrm{VP}) / \mathrm{PB}$ configuration of size $\mathrm{B}$ for at least 20,000 cycles, similar to the earlier cycling stability established for the $\mathrm{WO}_{3} /$ Poly-AMPS/PB configuration [15]. With periodic cycling, the darkened-state transmittance drifts upward with cycling, while that of the bleached state remains fairly stable. However, the cycling stability turns out not to be a complete enough measure of electrochromic lifetime, even at room temperature. This becomes evident as one examines the atrest stability. 


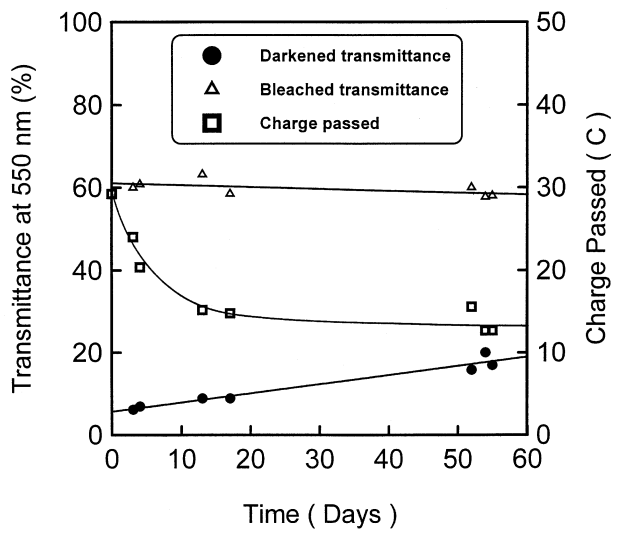

Fig. 6. Transmittance variations at $550 \mathrm{~nm}$ and charge passed as a function of time for a $\mathrm{H}_{x} \mathrm{WO}_{3} / \mathrm{P}(\mathrm{VSA}-\mathrm{VP}) / \mathrm{PB}$ cell of size $\mathrm{D}$, showing at-rest instability at room temperature.

\subsection{At-rest stability}

Fig. 6 gives at-rest stability data collected while monitoring a D-size display sample over two months. No data were collected during the displaying period, which spanned a month and accounted only for about 1,000 accumulated intermittent cycles, at $+1.2 \mathrm{~V}$ for darkening and $-0.6 \mathrm{~V}$ for bleaching. The cell was stored in the darkened state when at-rest. Presumably, the origin of the at-rest instability is due to the oxidation of the precharged $\mathrm{H}_{x} \mathrm{WO}_{3}$ electrode. The darkened-state transmittance at $550 \mathrm{~nm}$ drifts upward at about $7 \%$ per month and that of the bleached state drifts downward at about $1.5 \%$ per month. As a result, the transmittance window closes at a rate of $8.5 \%$ per month at $550 \mathrm{~nm}$, or $0.28 \%$ per day. Notice that there was a $57.0 \%$ loss of charge over 2 months period, even though the cell had only 1,086 cycles up to that point. On the other hand, bleached-state storage is not only much less stable, but also the degradation is unrecoverable compared to the degradation during darkened-state storage. This should not be too surprising, since at-rest instability was reported elsewhere for other truly complementary electrochromic systems, including $\mathrm{WO}_{3} / \mathrm{PB}[8]$ and $\mathrm{WO}_{3} / \operatorname{poly}(N$-phenylaniline) pairs [26].

\subsection{Rejuvenation}

The objective here is to confirm the importance of charge capacity matching and how it can affect the atrest stability of a large area ECD. This was verified with three transparencies of size $\mathrm{D}$, of the configuration $\mathrm{H}_{x} \mathrm{WO}_{3} / \mathrm{P}(\mathrm{VSA}-\mathrm{VP})$-primed Nafion $/ \mathrm{Pt} / \mathrm{PB}$. We noticed that samples of $\mathrm{H}_{x} \mathrm{WO}_{3} / \mathrm{P}(\mathrm{VSA}-\mathrm{VP})$-primed Nafion/Pt/PB, after storage in the darkened state, had suffered significant loss of visible transmittance in the bleached state. This is believed to be due to the presence of oxygen in the copolymer, which accelerates the self-discharging of the $\mathrm{H}_{x} \mathrm{WO}_{3}$ layer and thus the mismatch of two charge capacities. If the observed atrest instability is solely caused by oxidation of the $\mathrm{H}_{x} \mathrm{WO}_{3}$, it is expected that switching performance can be recovered fully by biasing a positive potential between a third electrode $(\mathrm{Pt})$ and the $\mathrm{H}_{x} \mathrm{WO}_{3}$ so as to compensate the lost charge.

Refreshing with a third Pt wire electrode was proven separately, on small samples of size B, to be an effective way for rejuvenating cells. In fact, by biasing a negative potential on the $\mathrm{H}_{x} \mathrm{WO}_{3}$ electrode with respect to the Pt electrode, it was also possible to partially refresh all three display samples of size $\mathrm{D}$, which already had lost $80 \%$ of their initial charge and exhibited hardly any switching. The rejuvenation was achieved with a third, Pt electrode, in the form of thin strip, by biasing +2.0 VDC between $\mathrm{Pt}$ and the $\mathrm{H}_{x} \mathrm{WO}_{3}$. The auxiliary $\mathrm{Pt}$ does not comprise any oxidizable or reducible substances and does not possess large capacity of charge. The purpose of the auxiliary electrode is only to readjust the charge capacity between two electrochromic layers. The rejuvenation time, ranging from $20 \mathrm{~min}$ to $2.5 \mathrm{~h}$, depended on the nature of contact between Pt and the polymer electrolytes. It was noted that the use of a third electrode for rejuvenation requires careful control of the rejuvenation time. When the rejuvenation time is longer than $2.5 \mathrm{~h}$, the undesirable electrolysis of water on positively charged Pt electrode becomes visible. The lost charge,

Table 2

Electrochromic samples of $\mathrm{H}_{x} \mathrm{WO}_{3} / \mathrm{P}(\mathrm{VSA}-\mathrm{VP})$-primed Nafion/Pt/PB under rejuvenation

\begin{tabular}{|c|c|c|c|c|c|c|}
\hline \multirow[t]{2}{*}{ Sample } & \multicolumn{3}{|c|}{ Before rejuvenation } & \multicolumn{3}{|c|}{ After rejuvenation } \\
\hline & $T_{550}(\%)$ & $\Delta \mathrm{OD}$ & $Q(\mathrm{C})$ & $T_{550}(\%)$ & $\Delta \mathrm{OD}$ & $Q(\mathrm{C})$ \\
\hline D-I & $24.6 \rightleftharpoons 32.5$ & 0.1210 & 3.39 & $15.0 \rightleftharpoons 54.2$ & 0.558 & 11.61 \\
\hline D-II & $28.1 \rightleftharpoons 30.0$ & 0.0284 & 3.36 & $16.8 \rightleftharpoons 58.0$ & 0.538 & 11.70 \\
\hline D-III & $28.8 \rightleftharpoons 34.5$ & 0.0780 & 3.36 & $20.0 \rightleftharpoons 56.2$ & 0.449 & 10.90 \\
\hline
\end{tabular}


Table 3

Electrochromic samples of various sizes switched at $+1.2 \mathrm{~V}$ and $-0.6 \mathrm{~V}$

\begin{tabular}{lllllll}
\hline Samples & Size $\left(\mathrm{cm}^{2}\right)$ & $T_{550}(\%)$ & $\Delta$ OD & $Q(\mathrm{C})$ & $\eta\left(\mathrm{cm}^{2} / \mathrm{C}\right)$ & $t_{\mathrm{d}}(\mathrm{s}) / t_{\mathrm{b}}(\mathrm{s})$ \\
\hline A-I & $4.8 \times 5.4$ & $3.0 \rightleftharpoons 64.5$ & 0.89 & 0.467 & 73.9 & $30 / 45$ \\
B-II & $10.2 \times 15.2$ & $6.0 \rightleftharpoons 71.5$ & 1.08 & 2.270 & 73.5 & $60 / 75$ \\
C-III & $16.0 \times 41.5$ & $4.3 \rightleftharpoons 64.5$ & 1.18 & 11.110 & 70.3 & $90 / 150$ \\
D-IV & $41.7 \times 41.7$ & $5.0 \rightleftharpoons 62.0$ & 1.09 & 24.990 & 76.1 & $150 / 240$ \\
\hline
\end{tabular}

in all three samples, was recoverable to $60-80 \%$ of original value and the bleached state transmittance was fully recovered. The less than complete recovery of darkened state transmittance after rejuvenation is associated apparently with the other $20-40 \%$ unrecoverable charge loss. The fact that the coulombic charge and transmittances were largely recoverable implies that the electrochromic system under investigation is a secondary battery, as opposed to a primary battery which is not rechargeable. Table 2 indicates the transmittance ranges at $550 \mathrm{~nm}$, optical density changes and passed charges before and after rejuvenation for all three samples of size D.

\subsection{Proposed degradation mechanisms}

Two different modes of degradation are proposed to explain the decline of EC performance under darkened and bleached-state storages. The following simple oxidation mechanism, Eq. (1a), is proposed to explain the recoverable charge loss under darkened-state storage. In the presence of $\mathrm{O}_{2}$ in the electrolyte, one would expect ECDs to shift to a partially darkened state from the fully darkened state during storage. This partially darkened state can be recovered to the fully darkened state after regeneration with a third electrode through Eq. (1b).

$$
\begin{aligned}
& \mathrm{H}_{x} \mathrm{WO}_{3} \cdot m \mathrm{H}_{2} \mathrm{O}+\frac{x}{4} \mathrm{O}_{2} \rightarrow \mathrm{WO}_{3} \cdot\left(m+\frac{x}{2}\right) \mathrm{H}_{2} \mathrm{O} \\
& \mathrm{WO}_{3} \cdot\left(m+\frac{x}{2}\right) \mathrm{H}_{2} \mathrm{O}+y \mathrm{H}^{+}+y \mathrm{e}^{-} \rightleftharpoons \mathrm{H}_{y} \mathrm{WO}_{3} \\
& \cdot\left(m+\frac{x}{2}\right) \mathrm{H}_{2} \mathrm{O} .
\end{aligned}
$$

On the other hand, experimentally, it was found that ECDs remain in the bleached state during bleachedstate storage. Permanent degradation observed in subsequent cycling, right after bleached-state storage, is probably due to hindrance by $\mathrm{H}_{2} \mathrm{O}$ in the zeolitic Prussian white, or PW $\left(\mathrm{PW}=\mathrm{M}_{4} \mathrm{Fe}_{4}^{\mathrm{II}}\left[\mathrm{Fe}^{\mathrm{II}}(\mathrm{CN})_{6}\right]_{3}\right.$, where $\mathrm{M}^{+}$is $\mathrm{H}^{+}$in our case). Thus, the extraction of protons from inside the PW films is inhibited, as indi- cated by Eq. (2). The degree of degradation depends on temperature and duration of cell storage in the bleached state.

$$
\begin{aligned}
& \mathrm{PB} \cdot n \mathrm{H}_{2} \mathrm{O}+4 \mathrm{H}^{+}+p \mathrm{H}_{2} \mathrm{O}+4 \mathrm{e}^{-} \\
& \quad \rightarrow \mathrm{PW} \cdot(n+p) \mathrm{H}_{2} \mathrm{O} .
\end{aligned}
$$

These conclusions are consistent with what has been observed experimentally: (1) EC samples shift to a partially darkened state from the fully darkened state during storage and the degradation is largely recoverable; (2) EC samples remain in the bleached state during bleached-state storage but the degradation observed in subsequent cycling, right after bleachedstate storage, is unrecoverable.

To further sort out and pinpoint the cause of degradation for the darkened and bleached-state storages, half cell $\mathrm{PB}$ and $\mathrm{WO}_{3}$ electrochemistry studies were conducted. Both $\mathrm{PB}$ and $\mathrm{WO}_{3}$ electrodes were switched individually in copolymer solution. Results indicated that the PB electrode became electrochemically less active (i.e., suffered high irreversibility) after an initial, galvanostatic bleaching. This rapid decline is expected, because water content is higher in the copolymer solution than in a laminated cell and proton hydration is believed to impart irreversibility. On the other hand, switching of $\mathrm{WO}_{3}$ in copolymer solution is reversible. Moreover, the loss of charge on a $\mathrm{H}_{x} \mathrm{WO}_{3}$ electrode after contact with air was found to be fully recoverable. It is concluded that the half cell PB electrochemistry can be used to explain the upward drifting of the darkened state transmittance either during cycling or at-rest storage. The unrecoverable degradation apparently arises from the incomplete conversion of Prussian white (PW) to PB. This is due to the retention of hydrated protons inside PW films, making them less electroactive upon further switching. Although partial rejuvenation of the device at room temperature was demonstrated, it is imperative to have a functioning third electrode, possibly an electroactive electrode, in order to achieve proper electrochemical stability at elevated temperatures. The need to incorporate a third electrode also implies that the devices have to be operated in an alternating cycling-refreshing mode, with intermittent charging on one of the electrodes. 


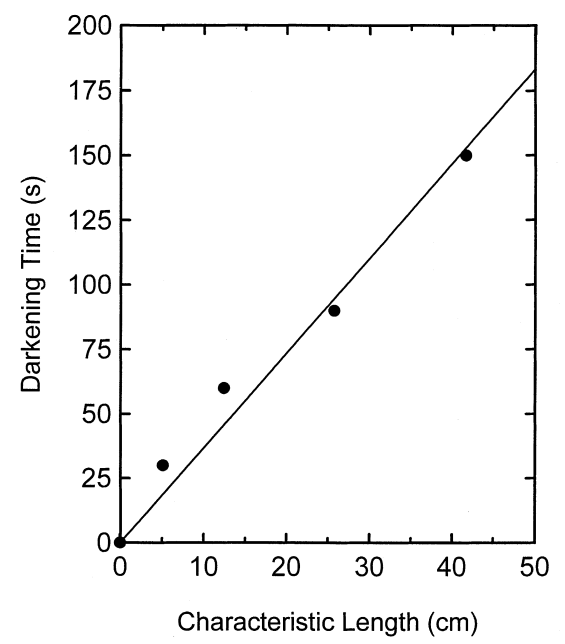

Fig. 7. Darkening times vs. square root of the active area for four samples with the $\mathrm{H}_{x} \mathrm{WO}_{3} / \mathrm{P}(\mathrm{VSA}-\mathrm{VP}) / \mathrm{PB}$ configuration.

\subsection{Scale-up}

Viennet et al. [27] and Randin [28] have shown, both theoretically and experimentally, that the switching time of an ECD increases with increasing active area. It was found in the present study, at constant temperature and switching potentials, that the switching times of the $\mathrm{H}_{x} \mathrm{WO}_{3} / \mathrm{P}(\mathrm{VSA}-\mathrm{VP}) / \mathrm{PB}$ electrochromic system are mainly determined by the size of the sample. Switching times were recorded for the four electrochromic samples with different sizes, mentioned above as $\mathrm{A}, \mathrm{B}, \mathrm{C}$ and D. Table 3 summarizes the switching results when samples were freshly darkened at $+1.2 \mathrm{~V}$ and bleached at $-0.6 \mathrm{~V}$.

Fig. 7 gives the darkening times at room temperature as a function of the square root of the active area for four samples with the $\mathrm{H}_{x} \mathrm{WO}_{3} / 2: 1$ vsa-vp copolymer/PB configuration. It follows from Fig. 7 that the darkening time is linearly proportional to the square root of the active area, regardless of the difference in the aspect ratio among samples. For all four samples switched at room temperature, the bleaching time took approximately 1.5 times as long as the darkening time. One common observation from the scale-up for the $\mathrm{H}_{x} \mathrm{WO}_{3} / \mathrm{P}(\mathrm{VSA}-\mathrm{VP}) / \mathrm{PB}$ complementary ECD was that the bleached state was non-uniform. The degree of non-uniformity increases with the cell size. That is, certain areas bleached out completely, while others developed residual color/pattern. Presumably, bleaching is more sensitive to variation in film thickness than darkening. This may eventually restrict the truly complementary system to only non-vision or lowtransmittance applications, such as a sunroof or shade band.

\section{Conclusions}

This work reports at-rest stability issues associated with the complementary, solid-state electrochromic configuration of $\mathrm{H}_{x} \mathrm{WO}_{3} / \mathrm{H}^{+}$-solid polymer electrolyte/ PB. The main conclusions from this study are:

(i) The key to approaching at-rest stability lies in the ability to first generate and then to maintain balanced charge capacity between the working and the counterelectrodes over extended periods of time. That is, the best performing complementary electrochromic device possesses nearly ideally matched charge capacities.

(ii) The prevention of the oxidation of the $\mathrm{H}_{x} \mathrm{WO}_{3}$ electrode before assembling is critical to the reproducible performance of the complementary electrochromic system.

(iii) A fairly good compatibility of the copolymer of vinylsulfonic acid (VSA) and 1-vinyl-2-pyrrolidinone (VP) with both Prussian blue and $\mathrm{WO}_{3}$ is verified by the additive property of the coloration efficiency of the complementary $\mathrm{H}_{x} \mathrm{WO}_{3} / \mathrm{P}(\mathrm{VSA}-$ VP)/PB system.

(iv) Degradation of the $\mathrm{H}_{x} \mathrm{WO}_{3} / \mathrm{P}(\mathrm{VSA}-\mathrm{VP}) / \mathrm{PB}$ electrochromic device during darkened-state storage is largely recoverable. Rejuvenation requires a third electrode and a biased potential between the $\mathrm{H}_{x} \mathrm{WO}_{3}$ and the third electrode. It is concluded from the rejuvenation operation that the major degradation mechanism for darkened-state storage is the oxidation of the $\mathrm{H}_{x} \mathrm{WO}_{3}$ electrode.

(v) Degradation of the $\mathrm{H}_{x} \mathrm{WO}_{3} / \mathrm{P}(\mathrm{VSA}-\mathrm{VP}) / \mathrm{PB}$ electrochromic device during bleached-state storage is unrecoverable. Bleached-state degradation is probably associated with hindrance by $\mathrm{H}_{2} \mathrm{O}$ in Prussian white.

(vi) The at-rest stability of the $\mathrm{H}_{x} \mathrm{WO}_{3} / \mathrm{P}(\mathrm{VSA}-\mathrm{VP}) /$ $\mathrm{PB}$ system requires control of oxygen and water content in the copolymer.

\section{Acknowledgements}

This work was partially done while the author worked at the Glass Technology Center, PPG Industries, Inc., Pittsburgh, PA. I am indebted to T.G. Rukavina for guidance in the preparation of copolymer electrolytes. I would like to thank Dr. C.B. Greenberg, of PPG Industries, Inc., for his assistance during the preparation of the manuscript. I also want to thank J.B. McCandless and J.B. Slobodnik for sample preparation. This work was also sponsored in part by the National Research Council of the Republic 
of China under contract numbers NSC 83-0402-E006017 and NSC 86-2745-E002-001R.

\section{References}

[1] H. Tada, Y. Bito, K. Fujino, H. Kawahara, Solar Energy Mater. 16 (1987) 509.

[2] H. Tada, Y. Bito, K. Fujino, H. Kawahara, in: L.T. Romankiw, T. Osaka (Eds.), Electrochemical Technology in Electronics, PV 88-23, The Electrochemical Society Proceedings Series, Pennington, NJ, 1987, pp. 325-337.

[3] Tada, H., Nagayama, H., Kawahara, H. US Pat. 4,726,664, 1988.

[4] M.A. Habib, S.P. Maheswari, M.K. Carpenter, J. Appl. Electrochem. 21 (1991) 203.

[5] M.A. Habib, S.P. Maheswari, J. Electrochem. Soc. 139 (1992) 2155.

[6] N. Oyama, T. Ohsaka, M. Menda, H. Ohno, Denki Kagaku 57 (1989) 1172.

[7] Miyamoto, T., Ura, M., Kazama, S., Kase T., Maeda, Y. US Pat. 4,645,307, 1987.

[8] Inaba, H., Nakase, K., Yanagida Y., Nishii, H. US Pat. 4,773,741, 1988.

[9] Kawai, M., Miyagi H., Ura, M. US Pat. 4,801,195, 1989.

[10] Kase, T., Kawai M., Ura, M. SAE Technical Paper Series, No. 861,362, 1986.

[11] T. Kase, T. Miyamoto, T. Yoshimoto, Y. Ohsawa, H. Inaba, K. Nakase, in: C.M. Lampert, C.G. Granqvist (Eds.), Large-Area Chromogenics: Materials and Devices for Transmittance Control, SPIE Optical Engineering Press, Bellingham, WA, 1990, pp. 504-517.

[12] K. Honda, M. Jujita, H. Ishida, R. Yamamoto, K. Ohgaki, J. Electrochem. Soc. 135 (1988) 3151.

[13] H. Ohno, H. Yamazaki, Solid State Ionics 59 (1993) 217.

[14] H. Inaba, M. Iwaku, K. Nakase, H. Yasukawa, I. Seo, N. Oyama, Electrochim. Acta 40 (1995) 227.

[15] K.-C. Ho, T.G. Rukavina, C.B. Greenberg, J. Electrochem. Soc. 141 (1994) 2061.

[16] A.W. Czanderna, C.M. Lampert, SERI Report No. TP255-3537, National Technical Information Service, Springfield, VA, 1990.

[17] A. Kutner, D.S. Breslow, J. Polymer Sci. 38 (1959) 274.

[18] T.G. Rukavina, in: K.-C. Ho, C.B. Greenberg, D.M. MacArthur (Eds.), Electrochromic Materials III, PV 96-24, The Electrochemical Society Proceedings Series, Pennington, NJ, 1997, pp. 36-53.
[19] C.S. Harris, T.G. Rukavina, Electrochim. Acta 40 (1995) 2315.

[20] K.-C. Ho, D.E. Singleton, C.B. Greenberg, J. Electrochem. Soc. 137 (1990) 3858.

[21] K.-C. Ho, J. Electrochem. Soc. 139 (1992) 1099.

[22] D. Ellis, M. Eckhoff, V.D. Neff, J. Phys. Chem. 85 (1981) 1225 .

[23] K.-C. Ho, in: K.-C. Ho, D.M. MacArthur (Eds.), Electrochromic Materials II, PV 94-2, The Electrochemical Society Proceedings Series, Pennington, NJ, 1994, pp. 170-184.

[24] Greenberg, C.B., Rukavina T.G., Singleton, D.E. US Pat. 5,124,832, 1992.

[25] R.D. Rauh, S.F. Cogan, J. Electrochem. Soc. 140 (1993) 378.

[26] L.H. Dao, M.T. Nguyen, in: M.K. Carpenter, D.A. Corrigan (Eds.), Electrochromic Materials, PV 90-2, The Electrochemical Society Proceedings Series, Pennington, NJ, 1990, pp. 246-260.

[27] R. Viennet, J.P. Randin, I.D. Raistrick, J. Electrochem. Soc. 129 (1982) 2451.

[28] J.P. Randin, in: C.M. Lampert, C.G. Granqvist (Eds.), Large-Area Chromogenics: Materials and Devices for Transmittance Control, SPIE Optical Engineering Press, Bellingham, WA, 1990, pp. 539-547.

\section{Bibliography}

Kuo-Chuan Ho received B.S. and M.S. degrees in Chemical Engineering from the National Cheng Kung University, Tainan, Taiwan, in 1978 and 1980, respectively. In 1986, he received the Ph.D. degree in Chemical Engineering at the University of Rochester. The same year he joined PPG Industries, Inc., first as a Senior Research Engineer and then, from 1990 until 1993, as a Research Project Engineer, both under the direction of Dr. Charles B. Greenberg. He has worked on the electrochemical properties of various electrochromic materials. He has applied surface science/interfacial engineering and electrochemistry/electrochemical engineering principles for improving the performances of electrochromic devices, with emphasis on electrochemical, atrest and thermal stabilities. Following a six years industrial career at PPG Industries, Inc., he joined his alma mater at the National Cheng Kung University in 1993 as an Associate Professor in the Chemical Engineering Department. In 1994, he moved to the Department of Chemical Engineering at National Taiwan University. Currently, he is a Professor there. 